\title{
L' ESECUTORE PRIVILEGIATO DI DIO: LA FIGURA DE MOISÉS EN LA OBRA DE NICOLÁS MAQUIAVELO
}

\author{
Eugenia Mattei \\ Universidad de Buenos Aires - IIGG - CONICET \\ eugeniamattei@gmail.com
}

\begin{abstract}
Resumen
Este artículo tiene como objetivo analizar las menciones y usos que realiza Nicolás Maquiavelo de la figura de Moisés en $I l$ principe y en los Discorsi. Maquiavelo realiza un particular tratamiento que es necesario seguir de cerca: es a partir de su análisis que podemos encontrar insumos para interrogar cómo operan los liderazgos en la obra maquiaveliana y cómo los líderes interactúan con el pueblo a través de un círculo pasional que se genera entre ambos. A estos efectos, procederemos en este artículo del siguiente modo: en primer lugar, restableceremos secuencialmente las menciones a Moisés en la obra de Maquiavelo. Solo una vez proporcionada esta reconstrucción nos dirigiremos al tratamiento de los ejes temáticos que resultan relevantes -la ausencia de la religión en Moisés, la crueldad, la tensión entre virtud y fortuna, y la relación entre líder y pueblo- con el fin de pensar la innovación teórica que estos ejemplos ilustran.
\end{abstract}

PALABRAS CLAVE: Moisés; Liderazgo; Pueblo; Maquiavelo.

\begin{abstract}
The aim of this article is to analyze the references and uses that Niccolò Machiavelli makes on the figure of Moses in $\mathrm{Il}$ principe and in the Discorsi. Machiavelli develops a particular approach, which must be followed closely: based on his analysis, we may find tools to examine how leaderships operate in his work, and how leaders interact with the people through a passionate circle that is generated between them. For these purposes, this article will proceed in the following way: In first place, we will sequentially restore the mentions on Moses in Machiavelli's work. Once this information is provided, we will focus on the treatment of the relevant concepts -the absence of religion in Moses, the cruelty, the tension between virtue and fortune, and the relationship between leader and people- in order to address the theoretical innovation that these examples portray.
\end{abstract}

KEY WORDS: Moses; Leadership; People; Machiavelli. 
La política, tal como la representa Roma, es una gestación preliminar de la propia generosidad mesiánica. Habrá que entregar el ser a la ley que, fruto de la animalidad, interrumpe la animalidad de las hordas humanas. El legalismo romano es el efecto positivo de su negatividad. "Reza por el Estado; sin él, los hombres se comerían unos a otros", declara una venerable Mishná del tratado Pirké Avot, enseñado en plena opresión del Imperio Romano.

Emmanuel Levinas, Más allá del versículo: Lecturas y discursos talmúdicos, Buenos Aires, Lilmod, 2006, p. 109.

\section{Introducción}

Sería imprudente buscar encasillar la figura de Moisés con algún calificativo. Es, más bien, un personaje huidizo: por ejemplo, parágrafos del Éxodo ${ }^{1}$ muestran un Moisés débil con un orgullo sacerdotal reprimido por su iniciador etíope (Éxodo 18: 13-27); otros, un líder liberador de un pueblo oprimido (Éxodo 3: 7-14) que puede ser capaz de asesinar a los hombres (Éxodo 2:11-12). La ambivalencia y las diferentes significaciones que se encuentran asociadas a él son capturadas por el propio Maquiavelo. Este último muestra, aunque no de una manera evidente, cómo en Moisés habita una contradicción. En Il principe, por un lado, Moisés es uno de los prototipos de "príncipe nuevo"2 pero luego se afirma que era un mero instrumento de Dios. En una referencia en los Discorsi Moisés aparece como un ejecutor que tiene en mira el bien común ${ }^{3}$. Moisés parece permanecer ahí, de manera ambigua, oscilando entre lo mitológico y lo real; entre un innovador y un mero hacedor de designios divinos.

¿Por qué dirigirnos a las menciones a Moisés en Maquiavelo? ¿Qué tipo de liderazgo condensa? ¿Qué nos dicen las afirmaciones, contradicciones y silencios de Maquiavelo en torno a esta figura? Maquiavelo realiza un particular tratamiento que es necesario seguir de cerca pues es a partir de su análisis que podemos encontrar insumos para interrogar cómo operan los

${ }^{1}$ Para la citas del Éxodo hacemos referencia a la Biblia de Jerusalén (DDB, Bilbao 1967), traducida de los originales por un equipo dirigido por J. A. Ubieta a partir de la versión francesa. De todos modos, preferimos citar haciendo referencia al Éxodo.

${ }^{2}$ Es el afamado capítulo VI de $I l$ principe: "De los principados nuevos que se adquieren con armas propias y con virtud".

${ }^{3}$ Antes de introducir por segunda vez la figura de Moisés, en Discorsi I.9 Maquiavelo hace referencia a la necesidad de estar solo para organizar una ciudad y velar siempre por el bien común "sin pensar en sí mismo". Luego de mencionar el caso de Rómulo y de Roma, Maquiavelo introduce a Moisés al decir "Se podrían citar numerosos ejemplos de lo dicho". 
liderazgos en la obra maquiaveliana y qué relación mantienen con el pueblo.

En ese contexto, es necesario revisar brevemente algunas tradiciones de pensamiento y análisis del momento maquiaveliano que se han ocupado de la república como concepto y como horizonte de sentido de la forma política moderna, sin poner el acento en la construcción de liderazgos y, otras que, enmarcadas en el estudio de las élites, han ignorado el lazo que estas mantienen con el pueblo. El análisis de estas tradiciones ilustra cómo se ha evadido la interrogación sobre la construcción de liderazgos en Maquiavelo que en nuestro articulo buscamos reinstalar a través del tratamiento de la figura mosaica.

La tradición republicana está articulada en torno a la figura de Maquiavelo. Los neorrepublicanos (Pocock 2008, Pettit 2010, Viroli 1999, Skinner 1998a, 1998b) han desarrollado, no sin matices, las nociones de republicanismo y de república y han instalado a Maquiavelo como el protagonista y fundador de esta tradición contraria, entre otras cosas, a la concepción liberal de libertad. Para el caso, Maurizio Viroli, P. G. A Pocock, Quentin Skinner y Philip Pettit han ubicado a la república de Maquiavelo como el concepto que puede salvar a la democracia de sus vicios liberales, pero sin convertirla en excesivamente popular o participativa. ${ }^{4}$

Por más que la tradición neorrepublicana posee importantes insumos heurísticos y de inspiración para nuestro trabajo, sobre todo en referencia al concepto "momento maquiaveliano", encontramos dos problemas. Primero, los neorrepublicanos, exceptuando a Skinner 6 , no han logrado entretejer la república maquiaveliana con aquellos liderazgos personales que menciona Maquiavelo; es más, en el caso de Pocock no hay un tratamiento de la literatura de Jenofonte, solo de la tradición aristotélica y su influencia en el pensamiento maquiaveliano. Segundo, la república eminentemente maquiaveliana no solo da cuenta del concepto de tumultos sino de la existencia de instituciones efectivas como eran los juicios populares

4 El reciente libro de John P. McCormick (2011) discute con la tradición neorrepublicana y propone, así, el concepto de democracia maquiaveliana.

${ }^{5}$ El "momento maquiaveliano" de Pocock consiste en la tensión entre virtudes clásicas y la virtù. Para este autor, estamos frente a un momento maquiaveliano cuando la república se enfrenta con el dilema de evitar la corrupción de las virtudes tanto de sus ciudadanos como de sus instituciones o, por el contrario, elegir la supervivencia de lo stato a través de la virtù del liderazgo personal. El problema de esta construcción teórica es que termina sosteniendo, tal vez, una oposición maniquea entre un maquiavelianismo republicano con uno decisionista.

${ }^{6}$ Skinner (1998b) reconoce más las ambivalencias maquiavelianas que los anteriores autores mencionados: advierte cómo Maquiavelo oscila entre el interés por las repúblicas y magistraturas y el papel de los príncipes, condottieri y líderes políticos tanto en aquellos momentos fundacionales como en el desarrollo de la república. 
y de revocatoria de mandato que proporcionaban el espacio institucional para la participación popular. Estas instituciones, articuladas con el pueblo y con liderazgos activos, no eran murallas para contener los cambios políticos, sino que, en determinadas circunstancias, fueron la condición de posibilidad para los mismos. Los juicios populares y de acusación ilustran cómo en la república maquiaveliana resulta muy difícil de homologar -no sin tensiones-al sistema de representación y al puro control formal de poderes.

La segunda línea de pensamiento analiza la cuestión de los liderazgos bajo el nombre de élites; lo hace, sin embargo, desentendiéndose de los problemas, interrogantes y giros del pensamiento y de la escritura maquiaveliana. El libro Los maquiavelistas. Defensores de la libertad de James Burnham (1986) ${ }^{7}$ es, en efecto, un claro ejemplo. En su título, Burnham ya anuncia cuál es su interés en el pensamiento de Nicolás Maquiavelo y su voluntad de explorar los principios de una ciencia política que se dirige desde el egregio Dante hasta la propaganda electoral del Partido Demócrata americano en las elecciones de 1932. Cabe destacar que su interés por Maquiavelo no implica una exégesis de su obra. Hay, más bien, una instrumentalización del corpus teórico maquiaveliano que tiene como fin establecer una categoría analítica: "los maquiavelistas". Este concepto le sirve para realizar dos lecturas para la comprensión de lo político, el poder y la ciencia. En la primera, están Dante y Sorel; y en la segunda, Gaetano Mosca, Robert Michels y Vilfredo Pareto. Estos últimos son considerados, efectivamente, los "herederos" de la enseñanza de Maquiavelo.

Ahora bien, ¿en qué consiste esa enseñanza? Maquiavelo, según Burnham, nos dice mucho. Primero, nos habla sobre la lucha del poder como tema de saber político, la contraposición entre élite y no élite y la irracionalidad de las acciones lógicas en política. Segundo, tanto para Burnham como para, parafraseando a Pocock, el "momento maquiaveliano" de Mosca (1986), Michels (1979) y Pareto (2000) prevalece un pueblo como mero trasmisor de influencia ${ }^{8}$, caprichoso e inconstante $^{9}$.

${ }^{7}$ El libro fue publicado a mediados de los años 40 bajo el fragor de la Segunda Guerra Mundial.

${ }^{8}$ Sobre este punto es necesario realizar una rápida sistematización de los puntos contrapuestos entre los representantes de la teoría de las élites y Maquiavelo. Mosca asevera que una clase política o dirigente es “(...) aquella minoría de personas influyentes en la dirección de la cosa pública, a la que la mayoría entrega, de buen o mal grado, la dirección (...)" (Mosca 1986, p. 107). Michels, por otro lado, ve la relación entre masas y élites, no de una manera tumultuosa y conflictiva. Por el contrario en la obra de Michels las élites son el resultado administrativo, organizacional si se quiere, del proceso progresivo de las democracias.

${ }^{9}$ La selección que realiza Burnham es de $I l$ principe el capítulo XVII donde se presenta 
El problema que encontramos en esta lectura propuesta por Burnham y en el análisis de los exponentes de las élites enfocados solo en la materialidad de las acciones de los líderes, es el olvido del plano simbólico que está presente en Maquiavelo y que nosotros trabajaremos en este artículo. Asimismo, la relación que mantiene el líder con el pueblo no es de una mera relación de opresión. En relación al debate con las teorías de las élites y las lecturas más procedimentalistas de la democracia, McCormick (2001, 2011) ha sistematizado las diferentes instituciones de la antigüedad romana que están presentes en la empresa teórica maquiaveliana para mostrar no solo el control del pueblo sobre las élites, sino también su disposición más activa y participativa. En este sentido, haciendo nuestro el argumento de McCormick, más que "maquiavelistas" Burnham tendría que haber utilizado el concepto "guicciardinista" en referencia al contemporáneo de Maquiavelo, Francesco Guicciardini ${ }^{10}$.

Por lo reseñado más arriba, creemos en la importancia de analizar cómo es el proceso de construcción de liderazgos en Maquiavelo. Para ello, nos valdremos, como hemos mencionado, de la figura de Moisés que se encuentra mencionada tanto en Il principe como en los Discorsi. En este sentido, la exégesis de Lefort (2010) resulta fuente de inspiración para nuestro objetivo. La interpretación de Lefort no es una mera interpretación de una obra del pasado, sino que encuentra en Maquiavelo la médula del debate contemporáneo: el atrevimiento de comprender la modernidad es, en definitiva, interrogar el enigma que la obra arroja sometiéndonos a "la experiencia de la imposible determinación de la distancia del yo al otro" (Lefort 1977, pp. 1268-1279).

La invitación de Lefort para pensar los liderazgos está inscripta en la relación entre los tumultos y el pueblo. Al hacer visible (y vidente) al pueblo, al conferirle a sus afectos la clave de la legitimidad del poder, Maquiavelo sentó, como argumenta Lefort, las bases para una política que no excluya a las masas. Al desnudar la maquinaria interna del poder, al exhibirlo desprovisto de su arcano, Maquiavelo hace visible ante los ojos del pueblo lo que sus dominadores velaban: que el poder no puede ser

un pueblo ingrato y voluble y de los Discorsi el capítulo LIII del libro I, donde aparece un pueblo caprichoso y embrutecido.

${ }^{10}$ Para McCormick (2003) los neorrepublicanos que dicen reivindicar a Maquiavelo no comparten la concepción popular de la república de este último. Por eso, y en particular por ser defensores de una concepción elitista de la política que heredó la democracia liberal, afirma que estos autores más que ser representativos del momento maquiaveliano lo son del momento "guicciardiniano", en referencia al amigo aristócrata de Maquiavelo que también escribió una versión de la historia de Florencia más centrada en las élites que en el pueblo como la de Il Macchia. 
ejercido por los príncipes sino al precio de contar con el consentimiento popular. Ahora bien, esa enseñanza debe ser entendida como algo más que una serie de consejos para que el pueblo sortee la opresión de los grandi: antes que nada, ha de ser entendida como una llave de acceso al espacio político para los hombres del pueblo. En efecto, Lefort pone particular atención a la función simbólica de lo político que inaugura Maquiavelo; a partir de ella, el pueblo adquiere la capacidad de descifrar el sentido de las acciones de los gobernantes, de prever las próximas, y de proyectarse él mismo en el juego político.

Desde este horizonte, el análisis del exemplum ${ }^{11}$ Moisés en Maquiavelo resulta una estrategia conceptual para poder entrever qué arquetipo de liderazgo está en juego en Maquiavelo. Esta figura operará como una especie de tipo ideal que ilustra dos aspectos fundamentales: primero, cómo es el proceso de construcción de liderazgo en Maquiavelo; segundo, qué conceptos maquiavelianos están en juego. Estos dos puntos dan cuenta de que la escritura de Maquiavelo, lejos de ser taxativa, es indirecta; su estilo opera bajo formas de alegorías y la figura mosaica es un ejemplo que insinúa al pensamiento del propio Maquiavelo. Asimismo, a través de los problemas que esta figura vehiculiza podemos ver la comunión entre el líder y el pueblo que tiene una particular formulación en Maquiavelo y ordena gran parte de los problemas que contiene su obra.

Estos aspectos tienen lugar a la luz de las siguientes preguntas que guían nuestro artículo: ¿cómo se construyen los liderazgos en Maquiavelo? ¿Qué lugar ocupa el pueblo? ¿Qué conceptos e interrogantes más generales ilustra la figura mosaica? La hipótesis de trabajo es que el proceso de construcción de liderazgo maquiaveliano se apoya en un cierto vínculo pasional entre el líder y el pueblo. O, puesto de manera distinta, un vínculo que no deriva de una cualidad del líder que le es inmanente, sino que es el efecto de ciertas pasiones --como el temor-que los sujetos sienten por el poder y por quien lo ejerce.

Hasta aquí el problema que incita este artículo y las preguntas que, a su vez, de él derivan. Hemos patentizado el objetivo general que se

${ }^{11} \mathrm{El}$ concepto de exemplum-exempla ha sido recuperado de los trabajos de Peter Bondanella $(1972,1973)$, pero en este artículo tomará un sentido renovado: no operará como parte de un género literario, ni se buscará contrastar a través de él, como lo hace Bondanella, la práctica de cómo aparecen los exempla en los clásicos humanistas y cómo está en Maquiavelo, sino, más bien, será puesto al servicio del trabajo de dilucidación de la siguiente cuestión: ¿cómo en esta noción de "arquetipos de liderazgos" están presentes, ya sea como forma alusiva, los interrogantes más generales de la empresa teórica maquiaveliana? Para ser más precisos, la escritura de Maquiavelo, indirecta y alusiva, deja entrever problemas fundamentales a través del exemplum Moisés. 
busca, la hipótesis que lo conduce, el corpus teórico indagado. Para llevarlo a cabo, a continuación, detallaremos cómo es la estructura de nuestro artículo. En primer lugar, restableceremos secuencialmente las menciones a Moisés en la obra de Maquiavelo. Luego, analizaremos la figura de Moisés en el Éxodo del Antiguo Testamento como insumo y fuente de interrogación para luego indagar la construcción que realiza Maquiavelo en torno a Moisés. Y, finalmente, nos dirigiremos al tratamiento de los ejes temáticos que resultan relevantes con el fin de pensar la innovación teórica que estas menciones vehiculizan. En resumen, el objetivo de este artículo no es encasillar la figura de Moisés bajo algún adjetivo o ver cuál es su efectiva presencia en el Antiguo Testamento. Más bien, si nos acercamos a la literatura bíblica, es como fuente de la lectura maquiaveliana. El objetivo de este artículo es, reiteremos, indagar a Maquiavelo como lector de Moisés y ver cuál es el uso que hace de la imagen mosaica para entrever, posteriormente, cómo es el proceso de construcción de liderazgo en Maquiavelo.

\section{Moisés en $I l$ principe y en los Discorsi}

Moisés aparece en dos capítulos -el VI y el XXVI- de los veintiséis de $I l$ principe y en cuatro capítulos de los Discorsi; dos veces en el primer libro (I.1; I.9), una vez en el segundo (II.8) y en una sola oportunidad en el tercer libro (III.30). Las menciones en Il principe se hallan en dos momentos claves del libro; primero, cuando Maquiavelo habla de aquellos héroes fundadores; segundo, cuando llama a Lorenzo II de Medici a liberar Italia y a imitar ${ }^{12}$ el proceder de los héroes fundadores: Moisés, Ciro y Teseo.

La primera mención se encuentra en el VI, "De los principados nuevos que se adquieren con armas propias y con virtud", aquel capítulo consagrado a la fundación del Estado. Antes de mencionar a Moisés, Maquiavelo comienza el capítulo adelantando que va a tratar sobre ejemplos de grandes hombres que fundaron principados nuevos. Y, desde una primera lectura, Maquiavelo parece aconsejar a aquellos hombres prudentes para que imiten a los notables ejemplos, si pretenden fundar órdenes. Cuando nombra a Moisés lo presenta como aquel que pudo convertirse en príncipe gracias a sus propias virtudes y no por medio de la fortuna:

\footnotetext{
${ }^{12}$ He aquí un artilugio argumental de Maquiavelo que es necesario resaltar: al decir que Lorenzo debe imitar a los héroes fundadores, Maquiavelo caracteriza al representante de los Medici como un mero imitador y no como un principe nuovo que crea nuevos órdenes y modos.
} 
Pero volviendo al caso de aquellos que se convirtieron en príncipes por sus propias virtudes y no por fortuna, digo que los más excelentes son Moisés, Ciro, Rómulo, Teseo y semejantes. Y si bien sobre Moisés no se debe argumentar, por haber sido él un mero ejecutor de las cosas que le ordena Dios, no obstante, debe ser admirado tan solo por esa gracia que lo volvía digno de hablar con Dios. ${ }^{13}$ (Maquiavelo 2012, pp. 27-28).

Moisés, entonces, es ubicado en el mismo nivel que otros fundadores como el rey de Persia -Ciro-, el mítico fundador romano -Rómulo- y el también mítico fundador de Atenas -Teseo-. Pero su figura es más particular que la del resto: luego de mencionar a los otros fundadores, Maquiavelo parece relegar a Moisés al lugar de "un mero ejecutor de las cosas que ordenaba Dios" para seguidamente decir que debe ser admirado "por la gracia que lo volvía digno de hablar con Dios". Es decir, realiza un desplazamiento que consiste en ubicar primero a Moisés en un lugar subsumido al de Dios para luego elevarlo a la condición de hombre "digno" que puede dialogar con Dios pues, en ese hablar, a diferencia del mero ruido, genera una apertura y un acercamiento de la distancia, que parecía tan insondable, entre la majestuosidad divina y su representante terrestre. Finalmente, en las próximas oraciones, Maquiavelo compara el proceder de Moisés con el de otros príncipes nuevos, como Ciro: "Y si consideran las acciones y disposiciones de ellos, parecerá que no discrepan de las de Moisés, que tenía por su parte un gran preceptor". Moisés es, entonces, virtuoso al igual que Rómulo, Teseo y Ciro, con la única diferencia de que tenía un "gran precettore”. En el siguiente párrafo, Maquiavelo realiza un tratamiento de la virtuosidad de Moisés que pudo ser entrevista al encontrar en la fortuna la ocasión para desplegarla, es decir, al encontrar a los hebreos oprimidos y esclavos en Egipto.

Casi seguidamente, Maquiavelo agrega que estos grandes hombres - convertidos en príncipes por caminos virtuosos- son también fundadores de nuevos órdenes y modos. Moisés, al igual que Ciro, Rómulo y Teseo, es el fundador de nuovi ordini e modi. Semejante empresa solo pudo llevarse a cabo gracias a su condición de profeta armado. A partir de aquí Maquiavelo incorpora una nueva figura que nos deja a nosotros, lectores,

${ }^{13}$ En la cita original en Italiano "Ma, per venire a quegli che per proria virtú e non per fortuna sono diventati principe, dico che li piú eccellenti sono Moisè, Ciro, Romulo, Teseo e simili. E, benché di Moisè non si debba ragionare, sendo uno mere essecutore delle cose che gli erano ordinate da Dio, tamen debbe essere ammirato solum per quella grazia che lo foceva degno di parlare con Dio" (Machiavelli 1971, pp. 30-31). Acá diferimos de la traducción de Ivana Costa con respecto a la traducción del verbo ragionare pues puede ser traducido por "discutir". 
perplejos: si estaba hablando de hombres excelentes, fundadores antiguos, ahora comienza con la introducción de un ejemplo contemporáneo que no refiere a un fundador sino a alguien acusado de herejía y ejecutado en la Piazza della Signoria. Este sacerdote, maestro, predicador y profeta, arribó a Florencia a pedido de Lorenzo el Magnífico en 1490. Pero con la caída del régimen de los Medici, la invasión francesa y la reorganización de la república florentina, Savonarola se transforma en un eminente profeta que "[subía] al púlpito para predicar sobre el profeta Ageo, sobre los Salmos y sobre Job" (Racanelli y Mazzitelli 2007, p. 30).

Frente a esta Florencia convulsionada, Savonarola exhortaba a la serenidad y clemencia de la población, predicando, a su vez, sobre la primacía del bien común sobre el privado y contra los prejuicios que habitaban en la tiranía. ${ }^{14} \mathrm{Si}$ la mención, como decíamos, es desconcertante, es porque el fracaso de Savonarola está para recordarnos que no todo se puede hacer con la oración, sobre todo porque el acto mismo de fundación requiere de la fuerza. Savonarola opera, efectivamente, como contrafigura de Moisés.

En el capítulo XXVI, el final de Il principe, en el llamado de acción a liberar a Italia de los bárbaros y en la apelación a introducir nuevos órdenes y modos, Lorenzo de Medici debe imitar el proceder de aquellos grandes hombres:

Habiendo considerado, pues, todas las cosas que hasta ahora se dijeron y pensando para mí mismo si actualmente en Italia corrían tiempos que permitieran honrar a un nuevo príncipe, y si había aquí una materia que diera ocasión a un príncipe prudente y virtuoso para introducir en ella la forma que le hiciese honor a él y bien a todos los hombres, me parece que son tantas las cosas que concurren en beneficio de un príncipe nuevo que no sé cuándo hubo un tiempo más propicio que este (Maquiavelo 2012, p. 136).

La escritura final de $I l$ principe de Maquiavelo produce, en este capítulo, un ascenso. El tiempo es el propicio para la llamada a la acción recordando la de los fundadores primigenios y honrosos. Entonces, si

14 "[Pero] dado que sería demasiado difícil reunir todos los días a todo el pueblo es necesario instituir un cierto número de ciudadanos que reciban esta autoridad de todo el pueblo: pero puesto que su reducido número podría ser corrompido por las amistades, relacionadas de parentescos y dinero, es necesario constituir un gran número de ciudadanos. (...) Conformado por lo tanto este grupo de ciudadanos, que se denomina Consejo Grande, y correspondiéndole distribuir todos los honores, no hay duda de que este es el señor de la ciudad (...)" (Savonarola 2007, p. 131). 
Lorenzo debe recordar aquellos grandes hombres es porque él no sería un hombre excepcional y estaría encomendado a imitarlos y, por lo tanto, a no innovar. Luego de esta evocación a Moisés, Maquiavelo parafrasea determinados elementos y relatos que se presentan en el Éxodo bíblico:

Aquí hay una grandísima disposición; y donde hay una gran disposición no puede haber gran dificultad, siempre y cuando aquella tome los órdenes que yo propuse como mira. Además de esto, aquí se ven hechos extraordinarios sin precedentes conducidos por Dios: el mar se ha abierto, una nube le ha indicado a usted el camino, la piedra ha derramado agua, aquí ha llovido maná; todas las cosas han concurrido hacia Su grandeza (Maquiavelo 2012, p. 138).

Primero, Maquiavelo hace referencia a aquel grandioso suceso en el cual, con la huida de los hebreos, las aguas del mar Rojo se abrieron milagrosamente a su paso para volver a cerrarse a tiempo para ahogar a sus perseguidores egipcios (Éxodo 14:21). Cuando Maquiavelo dice "la nube le ha indicado el camino" da cuenta de cómo Dios iba a ser el guía de los hebreos y permanecería en una nube para indicarles el camino desde que partieron en Sukkot y acamparon en Etam para comenzar la travesía en el desierto (Éxodo 13:20-22). Después tenemos las últimas dos referencias a intervenciones divinas. El Éxodo 17 comienza cuando la comunidad de los israelitas había partido del desierto de Sin y al acampar en Refidim no encontró agua para beber. En ese momento, el pueblo clamó por la ayuda de Moisés. El liberador del pueblo oprimido le clamó a Yahveh qué hacer. Este le comandó que pusiera sus manos sobre una piedra e hizo salir agua de ella (Éxodo 17:5-6). Con las palabras "aquí ha llovido maná", por último, Maquiavelo se refiere al milagro que realizó Dios frente al ruego del pueblo que, una vez liberado y estando en el desierto, clamaba por ser alimentado (Éxodo 16:12-15).

Respecto de los Discorsi, la primera mención de Moisés aparece en el libro I.1: "Cuáles hayan sido siempre los principios de cualquier ciudad y cuál fue el de Roma". Este capítulo comienza con el interrogante sobre el origen de las ciudades instituidas por hombres nativos y sobre aquellas que son instituidas por extranjeros. En la primera configuración Maquiavelo ubica a la Atenas de Teseo y a Venecia. En la segunda configuración, el fundador-siempre forastero-puede ser un hombre libre o depender de otro. Maquiavelo divide a los hombres libres que fundan ciudades entre los que obran por necesidad o los que lo hacen por libre elección: 
Las ciudades [son] fundadas por hombres libres cuando algún pueblo, bajo la dirección de un príncipe o por propia iniciativa, es obligado por las epidemias, por hambre o por la guerra a abandonar el país natal y buscar un nuevo asentamiento. Tales hombres, o habitan en las ciudades que encuentran en los países que conquistan, como hizo Moisés o las edifican de nuevo, como hizo Eneas. (Maquiavelo 2000, p. 30).

En esta tipología, nuestro autor ubica la figura de Moisés como el modelo de aquel príncipe que posee suma virtud al lograr hacer abandonar el país natal a un pueblo esclavizado en búsqueda de un nuevo asentamiento propicio para la fundación de su propia ciudad.

La segunda mención se encuentra en el Discorsi I.9 titulado "Que es preciso que sea uno solo el que organice de nuevo una república o el que la reforme totalmente sin tener en cuenta los usos antiguos". Maquiavelo comienza el capítulo introduciendo la figura de Rómulo para, posteriormente, excusarlo por haber cometido un fratricidio pues sus acciones estuvieron orientadas al bien común. ${ }^{15}$ La referencia a Moisés aparece junto a Licurgo y Solón los cuales, afirma Maquiavelo, pudieron atribuirse la autoridad de "redactar leyes adecuadas al bien común". Pero luego agrega que lo dejará de lado "como cosa ya sabida" (Maquiavelo 2000, p. 62).

En la tercera mención presentada en el libro II. 8, "Cuál es la causa de que los pueblos abandonen sus lugares patrios para invadir los países ajenos", volvemos a lo que ya Maquiavelo había mencionado al inicio de los Discorsi, esto es, a aquel pueblo que se ve violentado a dejar su territorio por la necesidad nacida por el "hambre o por la guerra". ${ }^{16}$ Aquí aparece Moisés en dos oportunidades asociado a aquellos que invaden otros territorios. Moisés y los invasores del imperio romano parecen ubicarse en el mismo plano. Esta guerra, a diferencia de las guerras por expansión, tiene como característica principal el hecho de que un pueblo entero se marcha a otro lugar. Es una guerra "cruel y pavorosa", pues tiene que "expulsar o matar a sus antiguos habitantes". En este sutil juego de asociaciones que Maquiavelo realiza nos interpela a nosotros, lectores, por la conexión que existe, en efecto, entre la fundación política y la conquista definida como la forma más cruel realizada por quien se dijo en la referencia anterior que "hacía leyes por el bien común". Leyes que, evidentemente, no incluyen el bien de los invadidos. Asimismo, en la

${ }^{15}$ Entonces, el anuncio directivo de "ser uno solo" significa, o se asocia de manera indirecta, a matar al hermano.

${ }^{16}$ Recordemos que a esta referencia le falta la epidemia como motor para abandonar el territorio que sí fue mencionada en la primera mención de Moisés en los Discorsi. 
última mención de Moisés presente en el capítulo, Maquiavelo hace referencia a cómo Moisés bautizó Judea -la parte de Siria ocupada por él- que es la misma característica que Maquiavelo les concede a los príncipes nuevos en el Discorsi I. 26.

Finalmente, la última mención de Moisés se encuentra presente en el libro III.30: "Un ciudadano que quiera emplear su autoridad para hacer alguna buena obra en su república deberá ante todo vencer la envidia; y cómo se debe organizar la defensa de una ciudad cuando llega el enemigo". La referencia a Moisés va a ser introducida luego de un tratamiento sobre la envidia como pasión:

Para vencer esta envidia, el único remedio es la muerte de los envidiosos, ${ }^{17}$ y si la fortuna es tan propicia al hombre virtuoso que muere por causas naturales, este llegará a la gloria sin escándalo, cuando sin obstáculo y sin ofensa pueda mostrar su virtud. Pero si no tiene esta suerte, le conviene pensar en el modo de quitárselo de en medio, y antes de hacer nada, conviene que tenga medios para superar esta dificultad. Y quien lea inteligentemente [sensatamente] la Biblia se dará cuenta de que Moisés se vio obligado, si quería que sus leyes y ordenamientos salieran adelante, a matar infinitos hombres, que se oponían a sus designios movidos solo por la envidia. (Maquiavelo 2000, p. 403).

Además de ser la primera y única mención explícita de la Biblia es, efectivamente, una aseveración enigmática: pues Maquiavelo afirma que quien lea sensatamente la Biblia se percatará de que existió una imperiosa obligación de "matar infinitos hombres" que resultaban "movidos por la envidia". A esta caracterización se contrapone nuevamente, igual que en Il principe, la contrafigura de Moisés, Girolamo Savonarola, pues este creía que podía desterrar la envidia solo con la bondad.

Ahora bien, ¿a qué se refiere Maquiavelo cuando dice leer sensatamente la Biblia? Para indagar sobre qué implica aquella aseveración tan taxativa, es necesario dirigirnos hacia el Éxodo y luego analizar los usos que hace Maquiavelo de la figura de Moisés.

${ }^{17}$ La envidia, al igual que el odio y el amor, es una pasión que Maquiavelo encuentra como perjudicial para la estabilidad de lo stato. Para justificar esto, Maquiavelo recurre, como es habitual en él, a los hechos históricos; más precisamente a las figuras de Manlio Capitolino y Piero Soderini. El primero, Capitolino, sentía una profunda envidia contra el reconocimiento, la gloria y el honor que gozaba Furio Camilio; una gloria que Capitolino consideraba injusta, por haber sido él -y no Camilo- el primero que había salvado el Capitolio y merecía, por lo tanto, las mayores alabanzas. Posteriormente, Capitolino generó intrigas en la plebe la cual provocó alborotos en la ciudad. 


\section{Moisés en el Éxodo}

En el Éxodo hay al menos cuarenta y tres conversaciones entre Dios [Yahveh] y Moisés. De estas conversaciones, treinta y tres son iniciadas por Dios, ya sea con el objeto de impartir una orden, comandarlo o predecir su horizonte futuro. Las restantes son iniciadas por Moisés en forma de desacuerdo o clamor. En referencia a aquellas iniciadas por Dios es menester resaltar tres episodios. Primero, en Éxodo 3:7-8, Yahveh le reconoce a Moisés la aflicción de su pueblo y afirma que ha bajado para acudir a sus penas e intervenir para otorgar la solución a la condición de miserabilidad en la que se encontraban. Segundo, en el Éxodo 12 Yahveh le proporciona las directivas e instrucciones a Moisés sobre el procedimiento de la ceremonia del Pesaj: la festividad de liberación del pueblo de Israel. Tercero, cuando los judíos estaban siendo perseguidos por los egipcios, el relato del Éxodo 14 expone la intervención divina en su sentido más radical: Yahveh sale a socorrer a los judíos al abrir el mar Rojo.

Contestó Moisés al pueblo: «No temáis; estad firmes, y veréis la salvación que Yahveh os otorgará en este día, pues los egipcios que ahora veis, no los volveréis a ver nunca jamás.

14 Yahveh peleará por vosotros, que vosotros no tendréis que preocuparos.»

${ }^{15}$ Dijo Yahveh a Moisés: «¿Por qué sigues clamando a mí? Di a los israelitas que se pongan en marcha.

${ }^{16}$ Y tú, alza tu cayado, extiende tu mano sobre el mar y divídelo, para que los israelitas entren en medio del mar a pie enjuto.

La omnipotencia divina, no obstante, parece diluirse en determinadas conversaciones, sobre todo aquellas iniciadas por el propio Moisés. En algunas de estas, Moisés declara sus dudas, ofreciendo excusas o quejándose de las órdenes de Dios. Al respecto, en el Éxodo 8 observamos una réplica de Moisés hacia Dios:

${ }^{5}$ Respondió Moisés a Faraón: «Dígnate indicarme cuándo he de rogar por ti, por tus siervos y por tu pueblo, para que se alejen las ranas de ti y de tus casas, y queden solamente en el río.»

${ }^{6}$ «Mañana», contestó él. Replicó Moisés: «Será conforme a tu palabra, para que sepas que no hay como Yahveh, nuestro Dios.

${ }^{7}$ Las ranas se apartarán de ti, de tus casas, de tus siervos y de tu pueblo, y quedarán sólo en el río.»

${ }^{8}$ Salieron Moisés y Aarón de la presencia de Faraón, invocó Moisés a 
Yahveh acerca de las ranas que afligían a Faraón,

${ }^{9}$ y Yahveh hizo lo que Moisés pedía: murieron las ranas de las casas, de los patios y de los campos.

${ }^{10}$ Las juntaron en montones y el país apestaba

Moisés le exigió a Yahveh que terminara con la calamidad de la plaga que infligía a los egipcios para que el faraón autorizara a los judíos a salir de Egipto. Como citamos en el parágrafo, Yahveh asintió al reclamo de Moisés. Esta cuestión revela, entonces, la reciprocidad que prevalece en esa relación Dios-Moisés. No solo Yahveh ejerce el lugar de imputación de autoridad; hay resquicio para pensar una correspondencia entre ambas figuras. Es más, luego de que Moisés recibiera el Decálogo en Éxodo 20, acontece una conversación entre Dios y Moisés en la cual el primero advierte al segundo: "¡Anda, baja! Porque tu pueblo, el que sacaste de la tierra de Egipto, ha pecado" (Éxodo 32:7). Efectivamente, la advertencia de Yahveh no era infundada: viendo que Moisés tardaba en bajar del monte Sinaí y no sabiendo si iba a bajar, el pueblo se reunió en torno a Aarón solicitándole un Dios. Frente a la demanda, Aarón realizó, con los aros de oro del pueblo, un becerro del mismo material para que el pueblo lo pudiera adorar y, sobre todo, exclamar: "Este es tu Dios, Israel, el que te ha sacado de la tierra de Egipto", Yahveh, furioso prorrumpió:

10 "Déjame ahora que se encienda mi ira contra ellos y los devore; de ti, en cambio, haré un gran pueblo."

${ }^{11}$ Pero Moisés trató de aplacar a Yahveh, su Dios, diciendo: “PPor qué, oh Yahveh, ha de encenderse tu ira contra tu pueblo, el que tú sacaste de la tierra de Egipto con gran poder y mano fuerte? (Éxodo 21:10-11)

Moisés logró, en efecto, torcer la voluntad de Yahveh. Y nos demuestra a nosotros, lectores, la reciprocidad que mencionamos al comienzo: Moisés pudo contener la furia de Dios hacia el pueblo judío. Pero cuando descendió del monte con las dos tablas de los mandamientos en sus manos, se acercó al campamento y observó aquel becerro de oro idolatrado por el pueblo que él había liberado, Moisés entró en una profunda ira y tiró las tablas. Es el descubrimiento por parte de Moisés de que su rebaño de hombres se había entregado a la idolatría del becerro y a los placeres de la carne. Luego, quemó al animal idolatrado y lo redujo a la precariedad del polvo, dejando entrever, así, una ira mayor a la divina. Recapitulemos: Moisés contuvo el enojo de Dios hacía el pueblo por idolatrar algo distinto a su majestad, para luego volverse él mismo contra este con una profunda ira. Es la presencia de un Moisés más autónomo 
que se yuxtapone constantemente con la de un Moisés que solo ejecuta los mandatos divinos. Ahora bien, retomemos el Éxodo 21 cuando Moisés retorna a Yahveh:
${ }^{31}$ Volvió Moisés donde Yahveh y dijo: “iAy! Este pueblo ha cometido un gran pecado al hacerse un Dios de oro.
${ }^{32}$ Con todo, si te dignas perdonar su pecado..., y si no, bórrame del libro que has escrito."
${ }^{33}$ Yahveh respondió a Moisés: "Al que peque contra mí, le borraré yo de mi libro.
${ }^{34}$ Ahora ve y conduce al pueblo adonde te he dicho. He aquí que mi ángel irá delante de ti, mas en el día de mi visita los castigaré yo por su pecado."
35 Y Yahveh castigó al pueblo a causa del becerro fabricado por Aarón.

En este diálogo, Moisés parece haber aprendido la necesidad del uso de la fuerza para poner a raya a aquellos que no se someten voluntariamente al orden de la ley. O, como dice la cita de Tito Livio en el último capítulo de $I l$ principe: “(...) pues es justa la guerra para quienes es necesaria y son impías las armas cuando no hay ninguna esperanza salvo en ellas" (Maquiavelo 2012, p. 138). ${ }^{18}$

A partir de las citas del Éxodo analizadas, podemos resumir tres dimensiones que están presentes en la figura de Moisés y que operarán como insumos para el posterior análisis del uso que hace Maquiavelo, a saber:

Primero, el Éxodo no muestra una lectura única de Moisés: se superponen continuas capas y matices que van desde un hacedor hasta un hombre con un gran poder de autonomía que puede ejercer su voluntad. Es más, la ira de Moisés, desatada por la adoración que tuvieron los judíos por la imagen del becerro, decantó en la ejecución de los cabecillas de los adoradores y en la afirmación de su autoridad.

Segundo, si concebimos el Éxodo como la historia de un pueblo, entonces la figura de Moisés se construye en relación a un pueblo que es, en definitiva, el verdadero protagonista. Como señala Taub, la importancia de Moisés "no es personal sino política -como líder de un pueblo o intermediario entre el pueblo y Dios- pues se trata de una historia política: una historia de esclavitud y libertad, ley y rebelión". ${ }^{19}$ Es la historia de la liberación de un pueblo que desea no ser servil, es una libertad pensada

${ }^{18}$ Maquiavelo reproduce esta cita en Discorsi III.12 y en el libro V. 8 de Istorie fiorentine.

${ }^{19} \mathrm{Al}$ respecto, hacemos referencia al estudio de Michael Walzer que Emmanuel Taub trabaja en su libro (Taub 2013, p. 27). 
como no esclavitud o, para decirlo maquiavelianamente, un pueblo ${ }^{20}$ que desea no ser dominado ${ }^{21}$. La construcción de figura de Moisés puede ser pensada, en este sentido, a través de la relación que mantiene con el pueblo, esto es, a través de cómo Dios elige a Moisés en un (segundo) pacto (divino) ${ }^{22}$ y cómo el pueblo, a través de ese pacto, se transforma, como dice el Éxodo 19, en un pueblo de sacerdotes ${ }^{23}$. Pero también, como asevera Cohen (2004), ${ }^{24}$ hay una doble relación que mantiene Moisés; una con Dios y otra con el pueblo. Por un lado, porque el rol de profeta de Moisés es el de un instrumento que constituye al pueblo judío a través de la liberación. Por otro, es el de intermediario de la revelación de la palabra divina. Para Cohen, el Éxodo 33 muestra que al hablar cara a cara Moisés con Dios

${ }^{20}$ En el Deuteronomio (20), uno de los cinco libros de Moisés junto al Génesis, el ya trabajado Éxodo, el Levítico y Números, es donde están presentes las leyes de la guerra dadas a Moisés para delimitar qué disposiciones deben tener los hombres que irán a la guerra. Lo que demuestran estas escuetas leyes para la guerra es cómo puede convivir en la figura del pueblo sacerdotal detallado más arriba, un pueblo eminentemente guerrero.

${ }^{21}$ Desde la tradición republicana, más específicamente con el trabajo de Pettit (2010), el deseo de no ser dominado de Maquiavelo resultó de insumo para pensar la no dominación como, efectivamente, ausencia de dominación que implica, en este sentido, la presencia de otros. Para Pettit la no dominación está asociada con el status de civitas y libertas que en la república romana eran homologables. De esta manera, la libertad republicana es una libertad civil pero con un ideal que hace, en este sentido, separarse de la libertad liberal. $\mathrm{Al}$ respecto: "Mientras la no dominación representa la libertad de la ciudad, la libertad como no interferencia tiende a representar la libertad del páramo (...). La no dominación, en el sentido que nos concierne, entonces, es la posición de aquel que disfruta cuando vive en presencia de otros y cuando, en virtud del diseño del entramado social, ninguno puede ser dominado por alguno de ellos". (Pettit 2010, p. 67). La traducción es propia.

La libertad como no dominación, en el sentido que nos compete es, entonces, el status, la posición de aquel que vive junto a otros y que en virtud del diseño del entramado social en el que se halla inmerso no es ni puede ser dominado por alguno de ellos.

22 Decimos segundo pacto pues, siguiendo el argumento de Taub, el primer pacto entre Dios, pueblo y líder se produce con la figura de Abraham.

${ }^{23}$ En Éxodo 19:1 «Al tercer mes después de la salida de Egipto, ese mismo día llegaron los hijos de Israel al desierto de Sinaí. ${ }^{2}$ Partieron de Refidim, y al llegar al desierto de Sinaí acamparon en el desierto. Allí acampó Israel frente al monte. ${ }^{3}$ Moisés subió hacia Dios. Yahveh le llamó desde el monte, y le dijo: "Así dirás a la casa de Jacob y esto anunciarás a los hijos de Israel: ${ }^{4}$ 'Ya habéis visto lo que he hecho con los egipcios, y cómo a vosotros os he llevado sobre alas de águila y os he traído a mí. ${ }^{5}$ Ahora, pues, si de veras escucháis mi voz y guardáis mi alianza, vosotros seréis mi propiedad personal entre todos los pueblos, porque mía es toda la tierra; ${ }^{6}$ seréis para mí un reino de sacerdotes y una nación santa.' Estas son las palabras que has de decir a los hijos de Israel."»

${ }^{24}$ En palabras de Cohen: "Pero Moisés mismo no es considerado como un mediador, aunque por otro lado sí lo era entre Dios e Israel. Es concebido únicamente como representante del pueblo; por eso no constituye una antítesis, un miembro aislado del pueblo en su totalidad" (Cohen 2004, p. 57). 
lo hace como un mensajero del pueblo. ${ }^{25}$ Moisés es así el líder político que lograr unificar el sentido de un pueblo a través de su figura y la palabra de Dios.

El tercer aspecto -vinculado con el anterior- es cómo el liderazgo de Moisés ilumina el interrogante sobre la ley. Tanto los mandamientos que están en el Éxodo como las leyes que Moisés reparte en Números y Deuteronomio reclaman para sí la presencia del pueblo. Pero, sobre todo, el momento en que Moisés recibe la ley de Dios en el monte Sinaí revela cómo aquel liderazgo es ejercido no solo para liberar a un pueblo de su condición esclavista, sino para mostrarse como el único representante legítimo de Dios en la tierra y, en ese sentido, condensa en sí mismo la potencialidad para disciplinar a aquellos que no acatan la ley (por ejemplo, Éxodo 21). Es en el propio Moisés donde se realiza un doble juego que implica, por un lado, ejercer la violencia hacia otros pueblos y hacia el propio, pero también "el aspecto profético que a través de la palabra de Dios le permite instalar un universalismo inclusivo gracias al cual el pueblo mismo se va agrandando y fortaleciendo (...)" (Taub 2013, p. 91).

Con el Éxodo pudimos reconstruir algunos aspectos del liderazgo de Moisés que siempre se encuentran vinculados al orden divino y al pueblo. Moisés es un personaje arcano donde conviven otras figuras yuxtapuestas como es la de representante privilegiado de Dios, un mediador de conflictos, un liberador de un pueblo que no es timorato en ejercer la violencia si un momento lo exige, y el de un profeta que es capaz de persuadir tanto al pueblo como a Dios. Luego de haber repuesto todas estas imágenes que se superponen continuamente nos dirigiremos ahora a los usos que hace Maquiavelo de Moisés.

\section{El exemplum Moisés: los usos y silencios de Maquiavelo}

En los apartados anteriores hemos reparado en las menciones de Moisés en Il principe y en los Discorsi y las diferentes configuraciones que existen de la figura de mosaica en el Éxodo bíblico. ${ }^{26}$ Si Maquiavelo realiza

25 Éxodo 33: "11 Yahveh hablaba con Moisés cara a cara, como habla un hombre con su amigo. Luego volvía Moisés al campamento, pero su ayudante, el joven Josué, hijo de Nun, no se apartaba del interior de la Tienda”.

${ }^{26}$ En $\mathrm{Il}$ principe, en el capítulo dedicado a soldados mixtos, auxiliares y propios (XIII), Maquiavelo menciona la historia de David y Goliat que pertenece al libro I de Samuel del Antiguo Testamento. Es interesante notar que este ejemplo resulta enigmático pues David no acepta las armas ofrecidas por Saúl y decide utilizar solo su honda y cuchillo para combatir contra Goliat. Luchar casi sin armas parece poner en entredicho aquella máxima maquiaveliana sobre que las armas son siempre el elemento fundamental. 
varias menciones de Moisés, da cuenta -aunque sin decirlo expresamentedel conocimiento de determinados episodios que están narrados en el Éxodo como hemos rastreado en las referencias bíblicas que hace en el capítulo final de $\mathrm{Il}$ principe.

No obstante, mantiene determinados silencios, como aquella omisión sobre Moisés como fundador de la religión, y realiza expresiones alusivas al relato bíblico - pero sin decirlo expresamente- como las que están presentes en el último capítulo de $I l$ principe. Por otro lado, hay afirmaciones más taxativas como la única mención explícita de la Biblia, las referencias a Savonarola a modo de contrafigura de Moisés y el ejercicio de la violencia como un elemento fundamental de toda conquista. ${ }^{27}$

Para poder tematizar ahora la figura de Moisés a través de conceptos fundamentales de la obra de Maquiavelo, en este nuevo apartado conduciremos la presencia del exemplum Moisés a tres ejes que se desprenden del tratamiento de dichas menciones: la ausencia de la religión en Moisés, la crueldad y la relación entre líder y pueblo. Es a través de estos conceptos e interrogantes que podremos capturar la especificidad y la densidad del exemplum Moisés y cómo es el proceso de construcción de un liderazgo. ${ }^{28}$

Vayamos, entonces, al primer eje: la omisión de Moisés como fundador de la religión. Un interrogante que, aunque no se presenta de manera explícita, ilumina la peculiaridad sobre la figura de Moisés

${ }^{27} \mathrm{El}$ ejercicio de la violencia está presente en otros fundadores, como es el caso de Rómulo. La fundación de Roma por parte de Rómulo tuvo como correlato un fratricidio: asesinó a su hermano Remo. Esta afirmación, efectivamente, puede escandalizar a cualquier pasión cristiana. Maquiavelo, en esta oportunidad, no disimula, no es un hipócrita. Nota la violencia, pero tampoco la exalta. Eso sí, reconoce y, a la vez, nos hace notar que Rómulo también crea el Senado. Al hacer mención a este hecho desplaza de la figura de Rómulo aquella imagen embrutecida de tirano. Es más, esta violencia pura es, sin embargo, episódica.

En este mismo sentido, la contraposición entre los reyes Agis y Cleómenes renueva y actualiza esa aseveración. El primero, Agis, fue asesinado por los éfores, funcionarios electos encargados de la política interior, por no poder imponer su voluntad por la fuerza. El segundo rey, Cleómenes, además de casarse con la viuda de Agis, mandó a matar a todos estos funcionarios y luego restauró propiamente las leyes de Licurgo. Nuevamente, como mencionamos en los otros apartados, la duplicidad maquiaveliana vuelve a operar en diferentes figuras - esta vez en Agis y Cléomenes- para mostrar la plasticidad de su discurso. Pero también Maquiavelo se desplaza de la república al principado y del principado a la república para hablar, luego, de las tiranías. Estos desplazamientos y giros demuestran cómo los Discorsi no se dedican solo a las repúblicas.

${ }^{28}$ Cabe destacar que estos ejes, en determinados momentos, se superponen por la afinidad que existe entre ellos. 
y sobre Maquiavelo, a saber: el silencio sobre la religión en Moisés. Leo Strauss (1978), en Thoughts on Machiavelli ${ }^{29}$, afirma que el silencio de un hombre importante siempre es significativo. Maquiavelo era un hombre importante, y si guardó silencio sobre algún aspecto importante no fue un hecho casual. Él habla de Moisés en Il principe -al igual que los demás fundadores que presenta en el capítulo VIcomo un hombre grande, excelentísimo, admirable, digno, virtuoso, fundador y profeta; en los Discorsi, por otro lado, aparece asociado a un conquistador con suma autoridad preocupado por el bien común. En ningún momento Maquiavelo habla, de manera explícita, sobre la fundación de la religión a través del Antiguo Testamento a manos de Moisés. En este silencio, sin embargo, se entrevén dos aspectos de la figura de Moisés.

Primero, el liderazgo de Moisés está dispuesto, como lo hemos señalado al referirnos al capítulo VI de Il principe, en el mismo horizonte que el de otros fundadores, a saber: Ciro, Teseo y, en algunos momentos, Rómulo. Moisés es un líder que posee un componente religioso pero es presentado junto a aquellos que no lo tienen; Moisés, entonces, parece no encontrarse en una situación de superioridad. Pero luego Maquiavelo realiza un movimiento contradictorio: dispone en la figura de Moisés una idea siempre adjetivada; Moisés fue un hacedor de las órdenes de Dios pero también, por esa capacidad que tenía de poder hablar con Dios, era un hombre digno. Este desplazamiento - de hacedor a digno- acerca a Moisés con Dios; o mejor dicho, a Dios con Moisés. Es más, si recordamos que Maquiavelo mencionó en el libro I.9 de los Discorsi que Moisés, al igual que Solón y Licurgo, se atribuyó una autoridad, aquella referencia confronta con la idea de un Moisés entendido como un mero instrumento de Dios y, más aún, se contrapone con lo dispuesto por el relato bíblico. Es decir, hay una nueva igualación, como se produce en $\mathrm{Il}$ principe, pero esta vez con dos "dadores de leyes" no inspirados en un principio religioso. En la narración de Maquiavelo sobre Moisés conviven, entonces, varios movimientos que se yuxtaponen: un Moisés que se encuentra en un pie

${ }^{29}$ No obstante, la afirmación no es propia, Strauss la extrae del propio Maquiavelo que la usa para notar el silencio de Tito Livio sobre la importancia del dinero en la guerra en Discorsi (II.10): "Pero Tito Livio es, con respecto a esta opinión, un testigo inigualable, pues reflexionando sobre si, en caso de haber ido Alejandro Magno a Italia, hubiera vencido a los romanos, afirma que hay tres cosas necesarias en la guerra: muchos y buenos soldados, capitanes prudentes y buena suerte, y examinando luego quién prevalecía en ellas, si Alejandro o Roma, llega a su conclusión sin mencionar para nada el dinero" (Maquiavelo 2000, p. 223). Para un estudio sobre la lectura straussiana de Maquiavelo véase Hilb (2005). 
de igualdad con otros héroes no religiosos y de igual forma admirable, un Moisés que se asigna para sí una autoridad; pero también un Moisés entendido como un instrumento de Dios.

Segundo, a través del exemplum Moisés podemos aprehender la disputa que mantiene Maquiavelo con la religión como fundamento de moralidad. Si Moisés estuvo obligado a "matar infinitos hombres", si tuvo que ejercer la crueldad, leer sensatamente la Biblia implica mostrar la enseñanza de una escritura sagrada alejada de lo que se entiende por bondad. Pero también en aquella disputa contra la religión como fundamento de la moralidad Maquiavelo hace operar un Moisés que, cuando libera a los hebreos y se aleja de su lugar patrio (II.8), funda una comunidad a través de una conquista "cruel y pavorosa" (I.9). Es más, si recordamos lo expresado en el Éxodo, la figura de Moisés no es la de un mero hombre bondadoso que libera a los oprimidos. Leer sensatamente la Biblia implica registrar aquello reparado en el Éxodo, específicamente en el Éxodo 2 y 21, en el que Moisés asesina a un egipcio y amenaza al pueblo liberado por adorar a un becerro.

El silencio sobre la religión de Moisés, como aquellos giros que van de un Moisés hacedor hacia un hombre digno, de un liberador hacia aquel fundador que ejerce la violencia sin par, ${ }^{30}$ deja entrever una apuesta que realiza Maquiavelo para la construcción de los liderazgos. Si Maquiavelo ubica a Moisés en pie de igualdad con aquellos liderazgos que no gozan de un componente religioso es porque la fundación en Moisés, Rómulo, Ciro, Teseo y, ahora agregamos, Licurgo y Solón, resulta ser una actividad humana y no divina; es decir, la ejerce un líder humano a través de su virtù. Maquiavelo, en este sentido, corre de escena a Dios para poner la virtuosidad de Moisés en primer lugar; una virtuosidad que no depende de lo divino. He aquí la virtù maquiaveliana: la virtù que se deja entrever en un líder como aquella capacidad de arquear las cosas y asumir para sí la autoridad en el acto mismo de fundación (I.9).

Ahora bien, vayamos al segundo eje: el de la crueldad. Este atraviesa el uso que hace Maquiavelo de Moisés y que está en plena sintonía con lo desarrollado anteriormente es -como en el caso de Borgia- el ejercicio de la crueldad como un punto medio entre la virtud y el vicio. Maquiavelo afirma que para llevar adelante la pretensión de su orden, Moisés tuvo que asesinar a "infinitos hombres", es decir, tuvo que ejercer la crueldad sobre esos hombres envidiosos. Esta mención opera, en un primer momento, para excusar la crueldad pues esta tuvo como bien loable el hecho de liberar a

${ }^{30}$ Sobre el interrogante de la relación entre fundación y violencia hay un interesante artículo de Volco (2014). 
los hebreos, pero también con esta aseveración nuestro autor logra hacer cada vez más borrosa la distinción existente entre el momento primigenio de la fundación de una comunidad y el ejercicio de la violencia como fue presentando en Discorsi II.8. Por más que la conquista realizada por Moisés, en aquel capítulo de los Discorsi, aparece asociada a las conquistas de los romanos y como estas siempre son "crueles y pavorosas", el ejercicio de la crueldad ilumina una novedad maquiaveliana: cómo se construyó un liderazgo popular con un buen uso de la misma.

Como ya hemos mencionado, en Discorsi III.30, Maquiavelo, luego de afirmar que Moisés ejerció la crueldad asesinando "infinitos hombres", realiza una advertencia: el éxito de Moisés no se explica solo por la fuerza sino por su actuar que implicó, siempre, un halo de audacia frente a una nueva situación. "Es la falta de fe en las cosas nuevas -señala Lefort-, no en la vieja imagen del Dios protector, lo que se opone a una reforma política" (Lefort 2010, p. 198). Como argumenta Lefort, el proceder de Moisés no implicó resguardarse en la comodidad del presente. Moisés se arriesgó hacia un futuro que, aunque con sus adversidades, no implica librarse de la previsión. Moisés fue audaz porque supo acoger la crueldad cuando la fortuna adversa así lo impulsó. Y con este ejercicio de la crueldad, Moisés pudo albergar en sí mismo la figura de un líder que deambuló entre el profeta persuasivo y el hombre capaz de ejercer la crueldad, de asesinar "si no tiene esta suerte" (Maquiavelo 2000, p. 409).

El liderazgo de Moisés queda expresado, entonces, en aquella habilidad de mostrarse como un mero y a la vez único instrumento de Dios y, a su vez, en hacer valer esa persuasión con el uso de la fuerza. Es decir, fue virtuoso en poder mostrarse como un representante privilegiado y también en ejercer la crueldad cuando su persuasión no bastaba. En aquella confianza en el futuro se le agrega un conocimiento de la "apertura" del mundo que implica una acción sin determinaciones y, a su vez, el éxito político puede derivar mucho más de este conocimiento que del "respeto" de algún "código moral" -de hecho, Maquiavelo razona "sanza alcuno rispetto" ${ }^{1}$-. Moisés mantuvo siempre, en sus acciones arriesgadas para enfrentarse a una fortuna abyecta,

${ }^{31}$ Hacemos referencia al Proemio del primer libro de los Discorsi: "Aunque por la naturaleza envidiosa de los hombres la tarea de encontrar nuevos órdenes y modos haya sido siempre tan peligrosa como buscar aguas y tierras ignotas, porque todos están más dispuestos a denostar que a loar las acciones ajenas, sin embargo, empujado por ese natural deseo que siempre ha existido en mí de obrar sin respeto alguno en aquellas cosas que acarrean común beneficio a cada uno, he decidido tomar un camino, el cual, como no ha sido recorrido todavía por nadie, me costará muchas fatigas y dificultades, pero también la recompensa de aquellos que consideren benignamente el fin a que se enderezan mis trabajos" (Machiavelli 1971, p. 123, la traducción es propia). 
una forma de actuar diferente a la de Savonarola como asevera en el capítulo VI de Il principe. En el cruce de Moisés y Savonarola -entre un profeta armado y un profeta desarmado respectivamente- notamos que Maquiavelo se concentra en la figura de Savonarola porque fue aquel profeta ejecutado por "[haber] sido incapaz de forzar a los hombres a conservar su creencia, no en Dios, sino en él y mantenerla" (Lefort 2000, p. 198). Savonarola no pudo construir una imagen que de él se desprende, como de la enseñanza de Moisés sí ocurre: el acto de institución como así su continuidad solo es asequible si se cuenta con la fuerza necesaria para imponerla y mantenerla.

Los dos ejes desarrollados hasta aquí -la omisión de la religión en Moisés y la crueldad- expresan cómo conviven en ese liderazgo la condición de su propia virtuosidad que no depende de lo divino, es decir, el acto de profesar y el ejercicio de la crueldad. Aquella oscilación, no obstante, se sostiene en un interrogante no solo inscripto en Maquiavelo, sino en la teoría clásica y contemporánea: la pregunta por la representación y la legitimidad. Al lograr Moisés mostrarse como aquel representante privilegiado de Dios para liberar a un pueblo esclavizado por el yugo egipcio, Maquiavelo pone en escena la pregunta por la legitimidad de ese orden. Pero ese interrogante no es formulado de manera aleatoria: corresponde al interés de pensar la legitimidad en relación a un otro específico que es el pueblo -y no otra cosa-.

Vayamos, entonces, al tercer eje que está presente en la construcción del liderazgo en Moisés y que es solidario a nuestra hipótesis de trabajo: el lazo que mantiene el líder con el pueblo. La primera relación que se establece entre Moisés y su pueblo -siguiendo a Maquiavelo y retomando el Éxodo del Antiguo Testamento- es la de un líder que se encontraba en el exilio y retornó para liberar a su pueblo de la esclavitud. Si el circuito que se establece entre el líder (Moisés) y el pueblo (judío) parece ser el acto de liberación de la opresión de los egipcios, podemos reponer categorías maquiavelianas para iluminar esta reciprocidad que se establece entre ambos. Hacemos referencia a aquel humor que es definido por la negativa en Maquiavelo: el de no ser dominado:

Porque en cada ciudad se encuentran estos dos humores diversos; y de eso nace que el pueblo desea no ser mandado ni oprimido por los grandes y los grandes desean mandar y oprimir al pueblo, y de estos dos apetitos diferentes nace en las ciudades uno de estos tres efectos: principados o libertad o licencia (Maquiavelo 2012, p. 49). ${ }^{32}$

32 En los Discorsi: "Creo que los que condenan los tumultos entre los nobles y la plebe atacan lo que fue la causa principal de la libertad de Roma, se fijan más en los ruidos y 
El humor de no de ser oprimido solo habita en el pueblo. En los Discorsi, la república romana-afirma Maquiavelo-llegó a su perfección, no a través de un sabio legislador -como fue el caso de Licurgo-, sino, más bien, por los accidenti; un acaecer que estuvo mediado por la disunione entre el popolo y los grandi. Hay un tono que subyace a esta afirmación de los accidenti: de la visible oposición entre el azar y la actitud de un sabio legislador, Maquiavelo pone en escena un conflicto que desgarró el caso romano. Los accidenti, en ese sentido, tienen su propia inteligibilidad: logran ordenarse a través del conflicto entre popolo y grandi, es decir, lograr poner un orden en el desorden:

Pero volvamos a Roma, la cual, aunque no tuvo un Licurgo que la organizase, en sus orígenes, de manera que pudiera vivir libre mucho tiempo, fueron tantos los sucesos que la sacudieron, por la desunión existente entre la plebe y el senado, que lo que no había hecho un legislador lo hizo el acaecer. De modo que, si Roma no fue favorecida por la mayor fortuna, sí fue afortunada de la otra forma que decíamos más arriba, ya que, aunque su primera ordenación fue defectuosa, no la desvió del recto camino que podía conducirla a la perfección (Maquiavelo 2000, pp. 38-39).

La disunione entre los grandi y el popolo abre así un espacio negativo que hace posible el intercambio simbólico entre ambas figuras: entre dos deseos contrapuestos; aquellos que desean dominar (los grandi) y aquellos que no desean ser oprimidos (popolo). Al respecto, Lefort problematiza esta cuestión:

Solo este deseo -que mantiene a raya a la potencia de los particulares, a la de los Grandes cuya existencia se define por una apropiación- es en efecto capaz por su propia naturaleza de abrir en la sociedad un espacio público, no el de las plazas y los pórticos, simples lugares de encuentro para las personas, donde la palabra circula entre alguien y algún otro, sino el espacio anónimo de la institución (Lefort 2010, p. 302).

gritos que nacían de esos tumultos que en los buenos efectos que produjeron, y no consideran [che e' non considerino] que en toda república hay dos espíritus contrapuestos: el de los grandes y el del pueblo, y todas las leyes que se hacen en pro de la libertad nacen de la desunión de ambos, como se puede ver fácilmente por lo ocurrido en Roma, pues de los Tarquinos a los Gracos transcurrieron más de trescientos años y, en ese tiempo, las disensiones de Roma rara veces comportaron el exilio, y menos aún la pena capital" (Maquiavelo 2000, pp. 41-42). En cursiva modificamos la traducción de Ana Martinez Arancón porque en el original figura en forma de negación: che e’ non considerino. 
Esta libertad como no dominación puede ser también leída, a través de la figura de Moisés, como una libertad pensada como no esclavitud. Moisés fue aquel líder extranjero exiliado que liberó a un pueblo sometido. Pero aquel acto de liberar no fue producido como un mero hecho de voluntad individual o divina. Lo que demuestra Maquiavelo con su análisis es que Moisés logró proyectar fuera de sí una imagen hacia el pueblo judío pero que, recordemos, osciló entre el profetizar y el persuadir, por un lado, y matar infinitos hombres, por otro.

En esa imagen proyectada, no obstante, Moisés da cuenta de un circuito que une y a la vez separa su figura y la de pueblo. Como hemos ya mencionado, el vínculo entre el pueblo y Moisés no es la no consecuencia de una cualidad inmanente que posee el propio líder. El lazo entre líder y pueblo es la deriva de una cierta tonalidad afectiva, el temor, que los sujetos sienten por quién ejerce el poder. Un poder que siempre tiene un halo de desgracia: "es la de no ver la imagen de sí mismo que ofrece a los demás" (Merleau-Ponty 1969, p. 271). Con esto, Merleau-Ponty argumenta -siguiendo estrictamente a Maquiavelo-que la política tiene que más que ver con la apariencia del poder que con su ser. Cuando Maquiavelo afirma que para conocer la naturaleza de los pueblos hay que ser príncipe, y que para conocer la del príncipe hay que ser pueblo, está hablando -dicho en el lenguaje de Merleau-Ponty- de una televisión o visión a distancia, una cierta distancia (écart) que hace posible la visión. En este sentido, la relación entre el príncipe y el popolo no está dada por una distancia taxonómica. Por el contrario, su tropo es un quiasma "que separa, y a la vez une, cualquier interacción humana" (Plot 2008, p. 118) Como con el tacto de nuestras manos, popolo y líder pueden verse, tocarse, pero solo al precio de mantener siempre una cierta distancia:

No, mis dos manos tocan las mismas cosas porque son las manos de un mismo cuerpo; pero cada una de ellas tiene su experiencia táctil; aunque tengan que tratar con un solo tangible, sucede que, de una a la otra, a través del espacio corporal -como también entre mis dos ojosexiste una relación muy especial que hace de ambas solo visión ciclópea (Merleau-Ponty 2010, p. 128).

De esta misma manera vemos la relación entre popolo-líder: un entrelazo, un circuito, que a través de la separación permite su unión. En suma, a través de este temor que pudo generar, Moisés muestra cómo el pueblo no es examinado como mero trasmisor de influencia, sino como un sujeto político clave para la construcción de su liderazgo, con el que se relaciona desde una distancia. 
Hasta aquí, hemos desarrollado los tres ejes -la ausencia de la religión en Moisés, la crueldad y la relación entre líder y pueblo- que caracterizan el liderazgo de Moisés. Esto nos ha permitido ver lo lejos que se encontraba Moisés de ejercer un liderazgo teológico, (es decir, es un líder humano que a través de su virtù corre de escena a Dios para poner en escena su propia virtuosidad humana), cómo en su figura ambigua se encuentra la disposición que debe tener un líder (profesar, persuadir, por un lado, y ejercer la crueldad, por otro) y, finalmente, cómo en todos estos aspectos el líder tiene como un interlocutor válido al pueblo.

\section{Moisés como función simbólica}

La virtuosidad de los grandes héroes nunca puede ser alcanzada por completo, pero para los que quieren instituir ordini nuovi operan como fuente de inspiración simbólica. El elemento simbólico en el pensamiento de Maquiavelo se alza allí donde parecía que solo importaba la verità effettuale della cosa, operando en dos aspectos. Un primer aspecto, como ya hemos mencionado, como inspiración para el actuar. O, para expresarlo con un contraejemplo, Savonarola no fue hábil para enaltecerse a través de una identificación imaginaria con los antiguos fundadores. Maquiavelo argumenta que para constituir un orden político nuevo se debe seguir el camino y la virtù de aquellos héroes más venerados que eran Moisés, Ciro, Teseo y Rómulo: "de manera que si la virtud de esos grandes hombres no llega, que le llegue al menos cierto olor de ella" (Maquiavelo 2012). Es así como la figura de los héroes cumple, también, "una función simbólica" (Lefort 2010, p. 195) y Maquiavelo se aleja de la imagen tradicional de la acción política: no es necesario que quien actúa políticamente se identifique con tales héroes, que imite sus acciones, sino más bien que se les "parezca", que desprenda algún aroma de esos fundadores. Un segundo aspecto remite a que lo simbólico revela cómo en aquel actuar se supone un saber, que a su vez se presenta arraigado en un no saber:

De tal suerte que la exigencia de una certeza científica y de una determinación de lo real se impone como lo que da su sentido al discurso y a la vez se revela suspendido a la verdad de un movimiento puramente crítico, ligado profundamente a la prueba de una incertidumbre que toca el fundamento del saber, o a la de una indeterminación relativa al Ser mismo de lo político (Lefort 2010, p. 199).

Al cargar en sí la empresa de la fundación, Moisés revela algo particular. En aquel acto de fundación Moisés está solo: persuade y ejerce 
la fuerza en soledad. Estar solo es la prueba de que no existe un acuerdo en la naturaleza que garantice el desafío de la fundación o de cualquier otra acción. En efecto, el Moisés de Maquiavelo exhibe que la ordenación providencial es un engaño; ridiculiza y combate el incitamiento por designios secretos. Es un alzamiento contra cualquier ordenación providencial que reclama para sí la legitimidad. A partir de aquí, visualizamos el horizonte de la incertidumbre que resulta habilitado por el uso que hace Maquiavelo de Moisés. Este último es lanzado en la aventura que tiene un saber: liberar a los judíos de la esclavitud. Pero aquel saber tiene como correlato lo incierto, aquello sobre lo que no hay ninguna certeza. Moisés tiene una lectura de su presente que lo lleva a hacer conjeturas sobre el futuro. Pero nunca tiene garantías que aten de manera definitiva su mirada al devenir de las cosas. Con esto queremos decir que Moisés no puede controlar de manera definitiva la voluntad de que lo que es ante sus ojos lo sea también ante los demás. Cualquier acción por más virtuosa que sea, entonces, siempre implica una apuesta.

\section{Moisés: un liderazgo demasiado humano}

A partir de las menciones de Moisés, del tratamiento del Éxodo, y de los ejes conceptuales que se derivaron, pudimos indagar cómo se construye el liderazgo de Moisés. Este proceso maquiaveliano implicó mostrar, principalmente, cómo la virtuosidad de Moisés estuvo alejada del principio divino. Asimismo, la edificación de este liderazgo mosaico en Maquiavelo implicó vislumbrar su condición pendular, su capacidad simbólica y, sobre todo, cómo todos estos elementos siempre están articulados en torno al pueblo. Por todo ello, Moisés es un exemplum de liderazgo maquiaveliano.

Franz Kafka, el 19 de octubre de 1921, escribió: "Moisés no alcanzó Canaán, no porque su vida fuese demasiado corta, sino porque era una vida humana"(Kafka 1975, p. 192). Moisés era humano, demasiado humano. Persiguió toda su vida la pista de Canaán pero muere justo antes de llegar a la tierra prometida. Este episodio demuestra el momento incompleto que constituye toda vida humana y la muerte como el envés de cualquier vida. Maquiavelo, en una afinidad con el relato kafkiano, destaca la humanidad de un líder que, a simple vista, parecía ser un símbolo de la religión judeocristiana. Maquiavelo se alza para desplazarlo, como mencionamos anteriormente, hacia el mismo lugar que se encuentran los más eminentes ejemplos de liderazgos no religiosos. Moisés fue un líder virtuoso no por haber hecho llover maná del cielo o hacer derramar de una piedra agua; el liderazgo de Moisés fue virtuoso porque 
tuvo una gran habilidad de mostrarse como el único representante legítimo de Dios y pudo proyectar esa imagen hacia el pueblo con el que construyó un lazo pasional. Pudo liberarlo de la opresión y comandarlo en el peregrinaje con una conciencia de lo que ocurrido.

Reiteremos: el Moisés de Maquiavelo no dio por sentada aquella legitimidad de ser el elegido de Dios y es por eso mismo que fue un virtuoso. Moisés, al oscilar entre la violencia y la persuasión, pudo revelar que el virtuosismo de su acción se midió por su eficacia. En el horizonte de lo indeterminado donde cada acción siempre está inscripta, existe una apertura de la partida para aquellos que están dispuestos a actuar, se aventuren a hacer algo, quizás, imprevisto. Y, en este sentido, Moisés fue eficaz: supo embarcarse, con su modo audaz, en las acciones más dificultosas por más que ello implicó no llegar a la tierra prometida.

El Moisés maquiaveliano es la vislumbre de un tipo particular de liderazgo y, sobre todo, de la figura de Moisés se pueden extraer dos enseñanzas del propio Maquiavelo. Primero, Moisés demuestra que el poder no descansa en la idea de una buena sociedad armoniosa. Hay una fractura fundamental entre egipcios y judíos donde los primeros desean dominar y los segundos solo buscan no ser esclavizados. En aquellos tumultos engendrados en el seno de esa misma comunidad, la figura de Moisés desplegó una imagen constituida a través del trato inmediato que tenía con Dios. Segundo, y en relación con lo anterior, la obediencia a la ley -los diez mandamientos- está dada por la virtù del propio Moisés y no por una providencia que rige los destinos de los hombres. Moisés, este humano demasiado humano, logró mostrarse y legitimarse como el único representante de Dios en la Tierra, como el l'esecutore privilegiato di Dio y es esa imagen la que desplegó hacia el pueblo que, a su vez, le permitió pendular entre el ejercicio de la violencia y el acto de profesar.

Estas dos enseñanzas muestran en el exemplum Moisés de Maquiavelo un trabajo de destrucción del componente teológico en la fundamentación de la autoridad. Por ello, el liderazgo de Moisés en Maquiavelo no es el de un mero instrumento de Dios. En él está inscripta la posición de un trasgresor. Este Moisés, ambiguo y trasgresor, en este sentido, también opera como autoalusión ${ }^{33}$ al propio Maquiavelo: como fundador de modi e ordini nouvi. Mientras el príncipe de Egipto y una de las primeras figuras del Mesías lo hizo con la espada y los libros de la ley, el secretario de la cancillería florentina lo hizo con la pluma y el habla persuasiva.

${ }^{33}$ En el artículo de Volco (2014) hay una mención de la autoalusión de Maquiavelo en relación a la fundación. 


\section{Bibliografía}

Bondanella, P. (1972), "Castracani: Machiavelli's Archetypal Prince", Italica, 49 (3), pp. 302-314.

Bondanella, P. (1973), Machiavelli and the Art of Renaissance History, Detroit, Wayne State University Press.

Burnham, J. (1986), Los maquiavelistas: Defensores de la libertad, Buenos Aires, Olcese.

Cohen, H. (2004), La religión de la razón desde la fuentes del judaísmo, Barcelona, Anthropos.

Hilb, C. (2005), Leo Strauss: El arte de leer: Una lectura de la interpretación straussiana de Maquiavelo, Hobbes, Locke y Spinoza, México, Fondo de Cultura Económica.

Kafka, F. (1975), Diarios (1910-1923), Barcelona, Lumen.

Lefort, C. (1977), "Lectures de la guerre: Le Clausewitz de Raymond Aron”, Annales: Histoire, Sciences Sociales, 32 (6), pp. 1268-1279.

Lefort, C. (1986), Le travail de l'œuvre Machiavel, Paris, Gallimard.

Lefort, C. (2010), Maquiavelo: Lecturas de lo político, Madrid, Trotta.

Machiavelli, N. (1971), Opere, Bertelli, S. (ed.), Procacci, G. (introd.), Milán, Feltrinelli.

Maquiavelo, N. (2000), Discursos sobre la primera década de Tito Livio, Madrid, Alianza.

Maquiavelo, N. (2012), El príncipe, Buenos Aires, Colihue.

McCormick, J. (2001), "Machiavellian Democracy: Controlling Elites with Ferocious Populism", American Political Science Review, 95 (2), pp. 297-313.

McCormick, J. (2003), "Machiavelli Against Republicanism On the Cambridge School's 'Guicciardinian Moments", Political Theory, 31 (5), pp. 615-643.

McCormick, J. (2011), Machiavellian Democracy, Cambridge, Cambridge University Press.

Merleau-Ponty, M. (1969), "Nota sobre Maquiavelo", en Signos, Barcelona, Seix Barral.

Merleau-Ponty, M. (2010), Lo visible y lo invisible, Buenos Aires, Nueva Visión.

Michels, R. (1979), Los partidos políticos: Un estudio sociológico de las tendencias oligárquicas de la democracia moderna, Vol I y II, Buenos Aires, Amorrortu.

Mosca, G. (1986), La clase política, Bobbio, N. (introd.), México, Fondo de Cultura Económica.

Pareto, V. (1975), Trattado di sociologia generale, Florencia, Sansoni. 
Pareto, V. (2000), The Rise and Fall of Elites: An Application of Theoretical Sociology, New Brunswick, Transaction Publishers.

Pettit, P. (2010), Republicanism: A Theory of Freedom and Government, Oxford, Oxford University Press.

Plot, M. (2008), La carne de lo social, Buenos Aires, Prometeo.

Pocock, J. G. A. (2008), El momento maquiavélico: El pensamiento florentino y la tradición republicana atlántica, Madrid, Tecnos.

Racanelli, C. y Mazzitelli, R. (2007), "Introducción”, en Savoranola, J. (2007).

Savonarola, J. (2007), Tratado acerca del régimen y gobierno de la ciudad de Florencia, Buenos Aires, Winograd.

Skinner, Q. (1978), The Foundations of Modern Political Thought, Vol. 1: The Renaissance, Cambridge, Cambridge University Press.

Skinner, Q. (1998a), Liberty before Liberalism, Cambridge, Cambridge University Press.

Skinner, Q. (1998b), Maquiavelo, Madrid, Alianza Editorial.

Strauss, L. (1978), Thoughts on Machiavelli, Chicago, University of Chicago Press.

Taub, E. (2013), Mesianismo y redención: Prolegómenos para una teología política judía, Buenos Aires, Miño y Davila.

Viroli, M. (1999), Repubblicanesimo, Bari, Editori Laterza.

Volco, A. (2014), "Moisés en la fundación maquiaveliana", Àgora Filosófica 14 (1), pp. 55-89.

Recibido el 14 de agosto de 2014; aceptado el 11 de junio de 2015. 